\title{
Expression and evolutionary divergence of the non-conventional olfactory receptor in four species of fig wasp associated with one species of fig
}

\author{
Bin $\mathrm{Lu}^{1,3,4}$, Nina Wang${ }^{1}$, Jinhua Xiao ${ }^{2}$, Yongyu $\mathrm{Xu}^{1}$, Robert W Murphy ${ }^{5,6}$ and \\ Dawei Huang*1,2
}

\begin{abstract}
Address: ${ }^{1}$ College of Plant Protection, Shandong Agricultural University, Tai'an, Shandong 271018, PR China, ${ }^{2}$ Institute of Zoology, Chinese Academy of Sciences, Beijing 100101, PR China, ${ }^{3}$ Chengdu Institute of Biology, Chinese Academy of Sciences, Chengdu, Sichuan 610041, PR China, ${ }^{4}$ Graduate School of the Chinese Academy of Sciences, Beijing 100049, PR China, ${ }^{5}$ Department of Natural History, Royal Ontario Museum, 100 Queen's Park, Toronto, ON M5S 2C6, Canada and 'State Key Laboratory of Genetic Resources and Evolution, Kunming Institute of Zoology, the Chinese Academy of Sciences, Kunming 650223, PR China

Email: Bin Lu - lvbin-3@163.com; Nina Wang - wangninagonewiththewind@yahoo.com.cn; Jinhua Xiao - xiaojh@ioz.ac.cn; Yongyu Xu - xuyy@sdau.edu.cn; Robert W Murphy - bob.murphy@utoronto.ca; Dawei Huang* - huangdw@ioz.ac.cn

* Corresponding author
\end{abstract}

Published: 20 February 2009

BMC Evolutionary Biology 2009, 9:43 doi:10.1186/147/-2148-9-43
Received: 27 June 2008

Accepted: 20 February 2009

This article is available from: http://www.biomedcentral.com/I47I-2/48/9/43

(C) 2009 Lu et al; licensee BioMed Central Ltd.

This is an Open Access article distributed under the terms of the Creative Commons Attribution License (http://creativecommons.org/licenses/by/2.0), which permits unrestricted use, distribution, and reproduction in any medium, provided the original work is properly cited.

\begin{abstract}
Background: The interactions of fig wasps and their host figs provide a model for investigating co-evolution. Fig wasps have specialized morphological characters and lifestyles thought to be adaptations to living in the fig's syconium. Although these aspects of natural history are well documented, the genetic mechanism(s) underlying these changes remain(s) unknown. Fig wasp olfaction is the key to host-specificity. The Or83b gene class, an unusual member of olfactory receptor family, plays a critical role in enabling the function of conventional olfactory receptors. Four Or83b orthologous genes from one pollinator (PFW) (Ceratosolen solmsi) and three non-pollinator fig wasps (NPFWs) (Apocrypta bakeri, Philotrypesis pilosa and Philotrypesis sp.) associated with one species of fig (Ficus hispida) can be used to better understand the molecular mechanism underlying the fig wasp's adaptation to its host. We made a comparison of spatial tissue-specific expression patterns and substitution rates of one orthologous gene in these fig wasps and sought evidence for selection pressures.
\end{abstract}

Results: A newly identified Or83b orthologous gene was named Or2. Expressions of Or2 were restricted to the heads of all wingless male fig wasps, which usually live in the dark cavity of a fig throughout their life cycle. However, expressions were widely detected in the antennae, legs and abdomens of all female fig wasps that fly from one fig to another for oviposition, and secondarily pollination. Weak expression was also observed in the thorax of PFWs. Compared with NPFWs, the Or2 gene in C. solmsi had an elevated rate of substitutions and lower codon usage. Analyses using Tajima's $D$, Fu and Li's $D^{*}$ and $F^{*}$ tests indicated a non-neutral pattern of nucleotide variation in all fig wasps. Unlike in NPFWs, this non-neutral pattern was also observed for synonymous sites of Or2 within PFWs.

Conclusion: The sex- and species-specific expression patterns of Or2 genes detected beyond the known primary olfactory tissues indicates the location of cryptic olfactory inputs. The specialized ecological niche of these wasps explains the unique habits and adaptive evolution of Or2 genes. The Or2 gene in C. solmsi is evolving very rapidly. Negative deviation from the neutral model of evolution reflects possible selection pressures acting on Or2 sequences of fig wasp, particularly on PFWs who are more host-specific to figs. 


\section{Background}

The interactions of flowers and insect pollinators are the classic examples of co-evolution. The intimate relationships and specialization between figs and fig wasps are among the best studied cases [1-3]. Pollinating fig wasps (PFWs) usually exclusively pollinate species of figs [2,4-7], although recent discoveries indicate that the species-specific association is much less specific than has been thought previously [8-13]. The pollinators completely depend on figs for their life cycles [14-17]. In addition to PFWs, several non-pollinating species of fig wasps (NPFWs) also exploit figs [18]. Evidently, non-pollinators are less specific to a given host species than pollinators $[13,18-23]$.

The host-specificity behaviour of insects relies heavily on olfaction [24], which has evolved to a level of extreme sensitivity and specificity [25]. This highly discriminative sensory mode is facilitated by an odour-activated seventransmembrane-domain G protein-coupled receptor (GPCR) that signals cascades [26]. Fig wasps are no exception. The mechanism underlying the host-specificity of fig wasps is almost certainly based on volatile chemicals released by the fig [27-29]. Fig wasps should be able to distinguish the particular odours emitted by hosts from other volatile compounds [30-32]. Different species of wasps appear to have unique volatile profiles which could account for host-specificity [28]. Such chemical constraints likely reduce host switching. Currently, investigations on adaptive changes in fig wasps are limited to morphological characters associated with an ecological niche [14,33-36]. For example, a pollinator must enter the syconium to deposit eggs. Thus, their antennae are easily broken to ease crawling through the ostiole. Unlike PFWs, most NPFWs cannot enter syconia. They usually possess a long ovipositor that is inserted through the syconial wall for egg laying [37-39]. Furthermore, both eyes and wings in most adult male PFWs exhibit highly vestigial traits, a correlate of living in the dark fig cavity all their life $[40,41]$. Unlike these attributes, very little is known about genetic changes in fig wasp's olfactory system.

As members of the GPCR superfamily, olfactory receptors (ORs) for odorous compounds play the critical role in the olfactory process [42]. The process consists of several linked systems ranging from stereo chemical recognition to the generation of an odour code in the brain. A characteristic trait of conventional odour ligand-binding OR types is the tremendous diversity of their sequences, often exhibiting only 20\% identities to each other [43-45]. A highly conserved, non-conventional member in the insect OR family is known as Or83b [46]. Orthologs have been identified from Drosophila melanogaster (DOr83b) [47-49], Anopheles gambiae (AgOr7) [50], Heliothis virescens (HvirR2) [51], Apis mellifera (AmelR2) [52] and others
[50,53,54]. Apparently, Or83b does not directly respond to odorants but rather acts as a chaperone receptor to form heterodimers with other odorant and pheromone receptors, thus ensuring dendritic localization [55-57].

While spatial expression patterns of conventional ORs are restricted in small subpopulations of olfactory sensory neurons (OSNs), Or83b is co-expressed with conventional ORs in most, if not all, neurons [52,55]. Tissue-specific expression patterns of putative ORs have been observed in ecologically distinct species. For example, in the hematophagous mosquitoes An. gambiae and Aedes aegypti, Or $83 b$ orthologs are expressed in the antennae, legs and proboscis (i.e., general gustatory organs). As such, Or83b orthologs may be involved in locating human hosts for blood feeding [50]. Sex-specific expression patterns occur in both mosquitoes and moths, for blood ingestion and mate searching, respectively [58-60]. Insects employ ORs to recognize and discriminate various quantitative or special odours in their ecological niche. Therefore, host specialization could reflect selection acting on ORs $[61,62]$. For example, bee-specific rapid expansion of the OR family presumably underlies their remarkable olfactory abilities, including perception of several pheromone blends, kin recognition signals, and diverse floral odours [45]. In Drosophila sechellia, rapid evolution and lack-of-function mutations in olfactory and gustatory receptor genes following a host shift reflect positive selection and/or relaxed constraints associated with an altered ecological niche [62].

In view of prior studies in mosquitoes and moths, different tissue-specific expression patterns of Or83b orthologs are expected to occur between resident male and hostsearching female fig wasps, or between PFWs that deposit eggs within the figs, and NPFWs that do not. If the tissuespecific expression patterns occur together with the crucial role of Or83b orthologs in locating a host, we can infer selection pressure on Or83b orthologous genes. The different degree of host specificity between pollinator and nonpollinators [13,18-23] likely makes Or83b orthologous genes subject to different magnitudes of selection. Our experimental group consists of one species of PFW (Ceratosolen solmsi) and three species of NPFWs (Apocrypta bakeri, Philotrypesis pilosa and Philotrypesis sp.), all associated with Ficus hispida. Herein, we identify Or83b orthologous genes in these four species of fig wasps, compare spatial expression patterns and substitution rate of these genes in fig wasps, examine possible evolutionary forces, and explore molecular mechanisms involved in co-evolution.

\section{Results \\ cDNA cloning}

The newly identified genes of C.solmsi, A.bakeri, P. pilosa and P. sp. were named as CsmOr2, AbOr2, PpOr2 and 
PsOr2, respectively, and the sequences were deposited in GenBank [Accession numbers: EU281848, EU281849, EU281850, EU281851]. The coding regions of these data had the same length in all fig wasp species (1422 bp when the stop codon was not considered). The length was same as in Nasonia vitripennis, but differed from Microplitis mediator by a one-codon indel ( $3 \mathrm{bp}$ ) and from Ap. mellifera by two indels. The amino acid (aa) sequences were extraordinarily conservative among our fig wasps, with $>90.3 \%$ identity (the percentage of identical matches between the two sequences over the reported aligned region) and > $96.4 \%$ similarity (the percentage of matches between the two sequences over the reported aligned region where the scoring matrix value is greater or equal to 0.0 ). This suggested that the four species of fig wasp are closely related relative to other species. Sequence identities ranged from $75.3 \%$ to $91.4 \%$ when compared with other hymenopteran orthologs including $N$. vitripennis, M. mediator and Ap. mellifera. Alignment of this non-conventional receptor and the other insects showed that the 19 protein sequences shared greater than $60 \%$ identity and $72 \%$ similarity. Remarkably, extreme conservation was discovered in the final 164 aa of the $\mathrm{C}$-terminal, where the 19 protein sequences shared nearly $90 \%$ identity.

We discovered the typical membrane topological structure of insect ORs in the four fig wasp Or2 protein sequences for seven putative transmembrane (TM) domains (Figure $1)$. The N-terminal of these receptors, located intracellularly $[56,63]$, occurred in all protein sequences. The putative membrane spanning domains were inferred to occur at similar relative positions in $\mathrm{CsmOr2,} \mathrm{AbOr2}, \mathrm{PpOr} 2$ and PsOr2. Remarkably, the N-terminal between TM 1 and TM 2 , and from TM 3 towards TM 4, contained the most variable regions. The variable second intracellular loop (IC2) connecting TM 4 and TM 5 was much longer than the other five loops.

\section{Phylogeny of the Or2 genes}

The phylogenetic analyses using 1st and 2nd codon positions showed that four fig wasp plus $N$. vitripennis Or2 genes formed a well-supported group (Figure 2; 100\% bootstrap support). A sister group relationship of Or2 genes was detected for $P$. pilos $a$ and $P$. sp. (99\% bootstrap support). The sequence of $N$. vitripennis was more closely related to Or2 genes of $P$. pilosa and $P$. sp. than to A. bakeri, although this association was weakly supported $(60 \%$ bootstrap). The Or2 gene of the pollinator was dissimilar to those of the three NPFWs. The hymenopterans Ap. mellifera and M. mediator clustered with the fig wasps plus $N$. vitripennis (100\% bootstrap support). All dipteran and lepidopteron sequences formed strongly supported groups ( $97 \%$ and $100 \%$, respectively). Removal of the sequence of Ceratitis capitata from the analysis did not affect tree structure. Thus, the sequence was retained in subsequent analyses. Use of aa sequences instead of 1 st and 2 nd codon positions yielded a nearly identical tree topology except that $N$. vitripennis first clustered with $A$. bakeri (47\% bootstrap support) and then formed a group with $P$. pilos $a$ and $P$. sp. (98\% bootstrap support) (tree not show). When we used a Sankoff (step matrix) in PAUP* [64] to force the minimum number of mutations (steps) required to transform from one aa to another, we obtained the same trees found without using the matrix (tree not show). The difference in tree topologies likely resulted from a difference in potentially parsimony informative characters between the aa data (210 sites) and 1 st and 2 nd nucleotide codon positions (355 sites).

\section{Tissue specificity of expression}

Following PCR for tissue specific-expression (Figure 3), all bands were the size expected from the primer design ( 330 bp). Bands of similar intensities obtained with primers specific to the actin control indicated the integrity of the cDNA preparations. The intensity of the products (relative to an internal control) indicated variable levels of expression in different tissues. Strong expressions of this ORtype occurred in male heads (including antennae and maxillary palps) and in female antennae, in PFW and all types of NPFW. Lower levels of expression were discovered in the abdomens and legs of females in all species of fig wasp. In contrast to female NPFWs, a band of lower intensity was also obtained with cDNA from the thorax of female C. solmsi. No transcripts were detected within nonolfactory tissues (e.g., thorax, abdomen and legs) of all males. In all cases, actin amplifications were more robust for tissue templates, reflecting higher template quantities in the parallel control reactions. This further demonstrated the absence of detectable expression of ORs in non-olfactory tissues. Finally, to confirm this pattern, an additional 10 cycles of PCR were added to the protocols. Even under these extremely sensitive conditions, RT-PCR products were not detected in all male non-olfactory tissues and in female NPFW thoraxes. Genomic contamination of cDNA templates was clearly distinguishable from cDNA products by primers that spanned predicted introns (data not shown). To verify their specificity, the RT-PCR products from each tissue cDNA were sequenced, revealing that a specific product had indeed been obtained in each instance.

\section{Selection pressure on individual amino acid sites}

Because adaptive evolution usually occurs on a small region of a gene's sequence and can even be restricted to a single aa site [65-67], we sought aa sites that were subjected to selection pressure. Selection pressure can be inferred from the ratio of nonsynonymous to synonymous changes, Ka/Ks (also known as $d_{N} / d_{S}$ or $\omega$ ). When $K a / K s=1$, neutral selection is indicated and when $K a / K s>$ 1 , positive selection is implied. Alternatively, when $\mathrm{Ka} / \mathrm{Ks}$ 

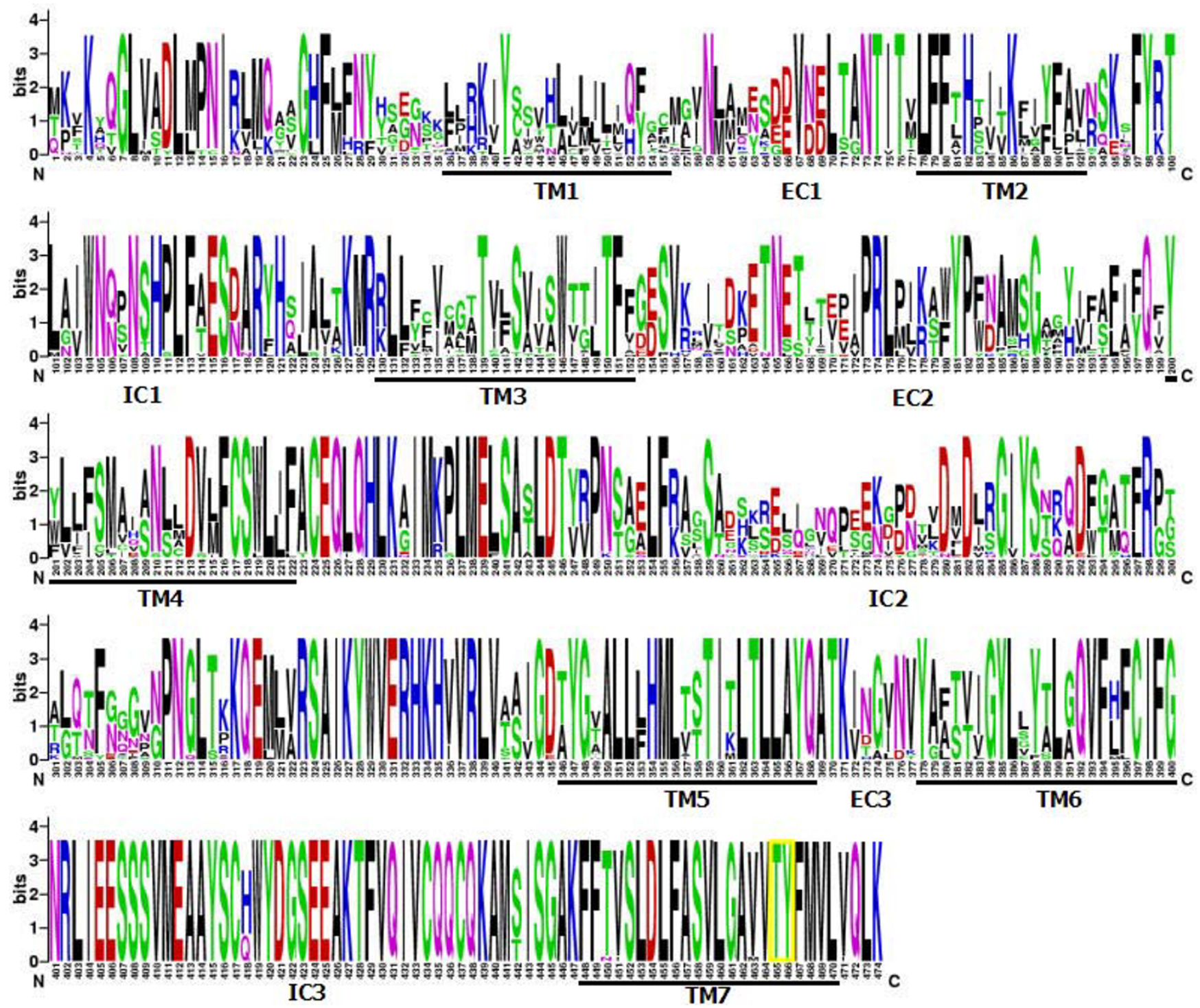

Figure I

Alignment of Or83b orthologous amino acids in insects. Conservation of amino acid sequence is displayed as a sequence logo. The relative frequency with which an amino acid appears at a given position is reflected by the height of its oneletter amino acid code, with the total height at a given position proportional to the level of sequence conservation. Transmembrane domains (TM I-7) and extracellular (EC) and intracellular domains (IC) are numbered and indicated. Threonine (T) and tyrosine $(\mathrm{Y})$ residues that are sites of potential phosphorylation are enclosed in heavy yellow boxes.

$<1$, purifying selection is suggested [68]. In the present study, two thresholds for significance ( 0.1 and 0.2 ) were taken into account in order to identify residues potentially involved in ligand-binding activities. In our analysis, $\mathrm{Ka} /$ $K s=0.0844161 ;$ no positively selected nucleotide sites were detected at the $P<0.1$ in the SLAC analysis. However, 380 of 474 aa sites were negatively selected. Or2-type receptors appeared to be primarily negatively selected. When significance level was adjusted to $P<0.2$, one positively selected site was discovered at the 21 st aa $(P=$ $0.157371)$. Serine $(S)$ occurred at this position in the
PFWs, but all NPFWs had Glycine (G). The other species of insect displayed various amino acids at this site, including Isoleucine (I), Alanine (A), Tyrosine $(\mathrm{Y})$, Leucine $(\mathrm{L})$, Methionine $(\mathrm{M})$ and $\mathrm{G}$, but not $\mathrm{S}$.

\section{Analyses of substitution rate}

Substitution rates were estimated for synonymous and nonsynonymous sites within the 1365 bp Or 2 sequences. The same data [Accession numbers: FJ606763] were collected from a closely related species of C. solmsi, Ceratosolen cornutus, which is the pollinator of Ficus auriculata. This 


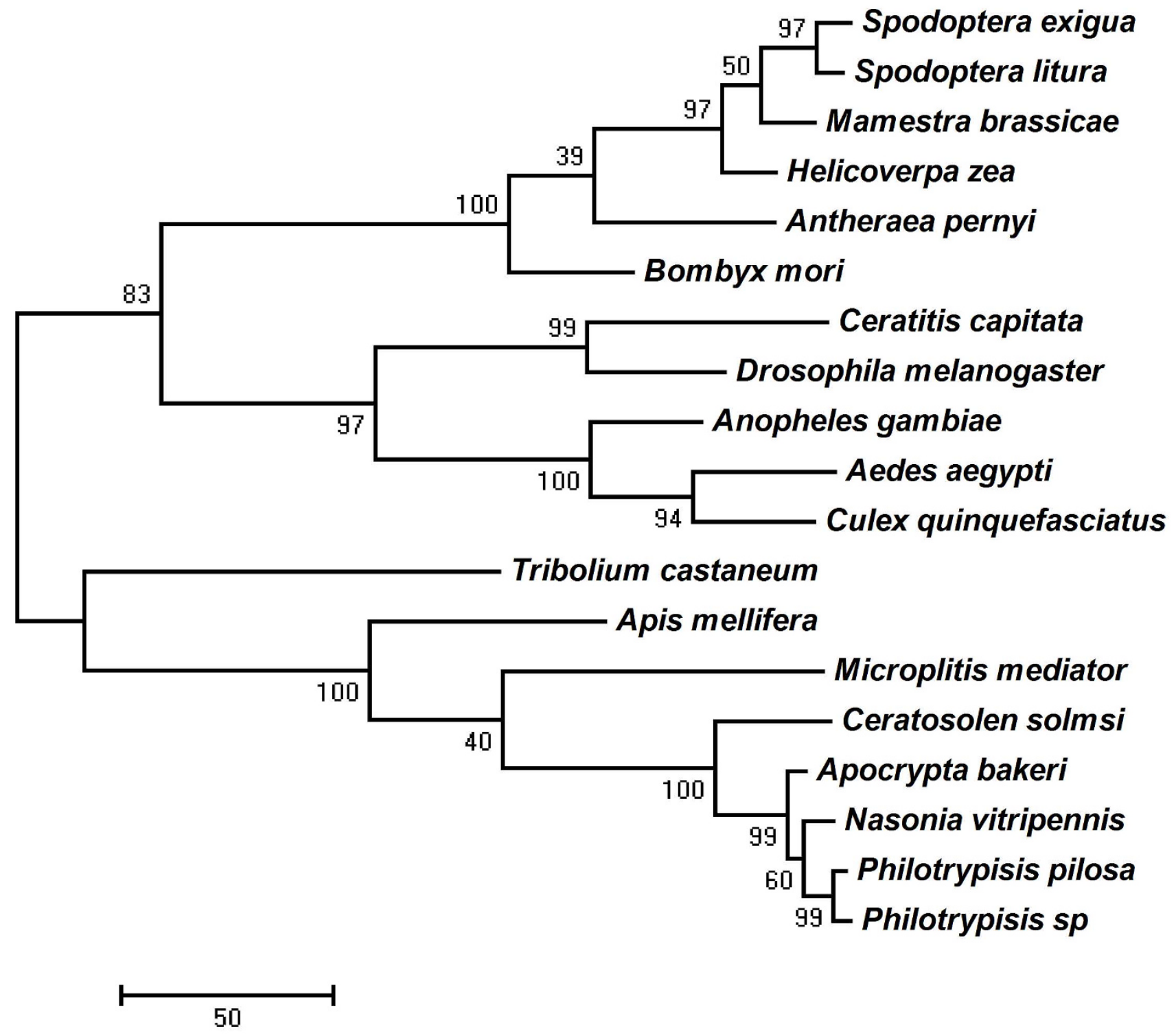

Figure 2

The maximum parsimony tree of Or2 genes from fig wasps. The MP phylogram was constructed based on Ist $+2 \mathrm{nd}$ codon positions. The reliability of each tree node was assessed by bootstrap proportions with 1000 replications. Branch lengths are proportional to change.

addition increased the statistical power of the comparison of substitution rates [69]. Estimations of synonymous substitutions per synonymous site $(K s)$ between the dipteran species and C. solmsi ranged from 2.1785 to 3.1533 (Table 1). However, the estimates between the dipterans and C. cornutus were much lower, ranging from 1.3811 to 1.5638 only. In contrast, the rather similar estimates of substitutions occurred both between the dipterans and $P$. pilosa (1.1044-1.4665) and between the dipterans and $P$. sp. (1.0173-1.4974). Estimations of the number of nonsynonymous substitutions per nonsynonymous site $(\mathrm{Ka})$ were slightly higher between the dipterans and C. solmsi (0.3064-0.3511) than between the dipterans and C. cornutus (0.2995-0.3373). The elevated substitution rate of the Or2 gene in C. solmsi also occurred when the analyses involved other hymenopterans (N. vitripennis and Ap. mellifera) instead of dipterans. Between-species comparisons in pollinators (Ceratosolen) yielded higher values of both $K s$ and $\mathrm{Ka}$ than in non-pollinators (Philotrypesis) (Table 1).

Tajima's relative rate test [70] detected a significant difference in the rate of synonymous substitutions between $C$. 


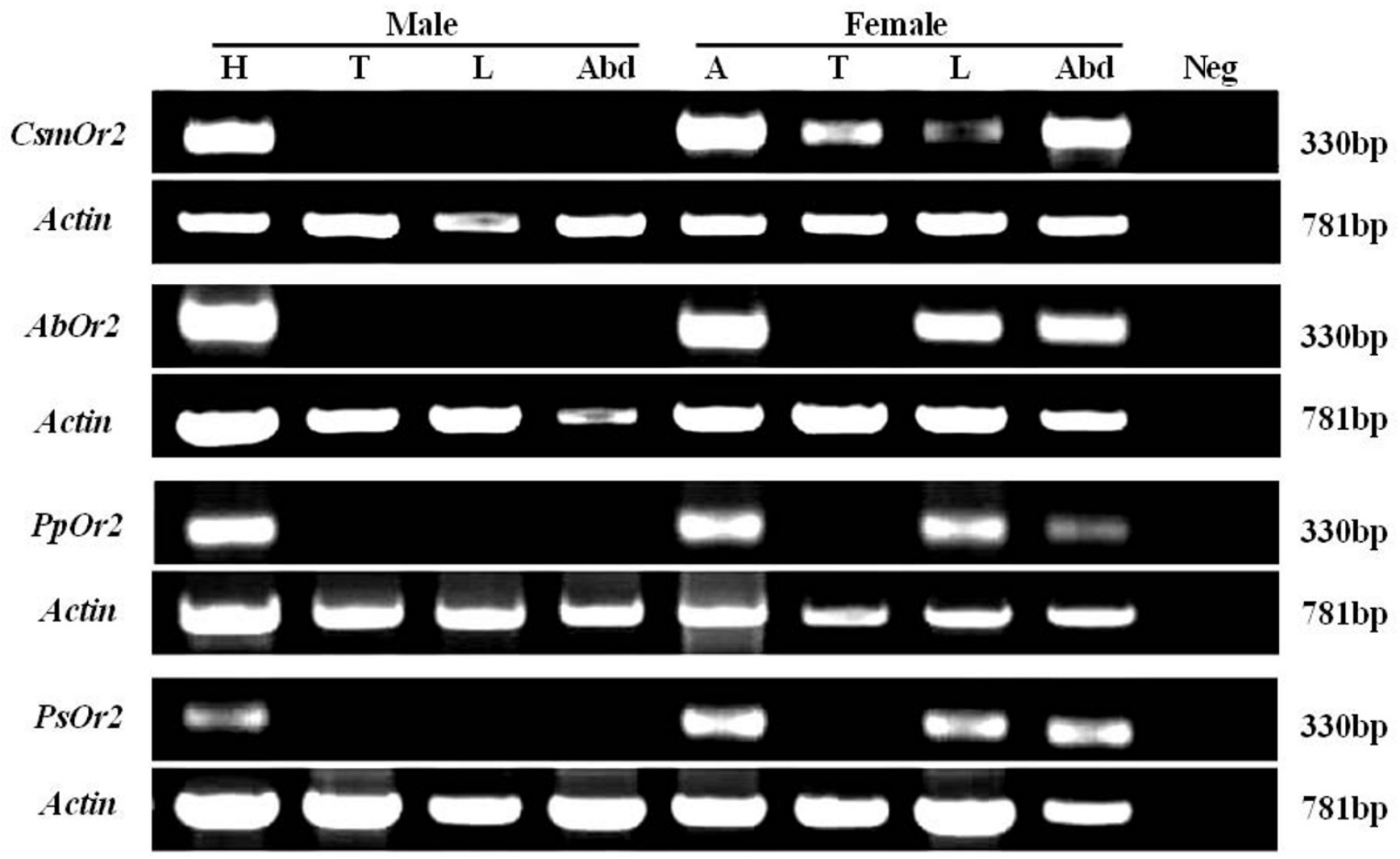

Figure 3

Olfactory tissue-specific expression of Or2 genes in fig wasps. RT-PCR was performed with cDNAs prepared from different species and tissues of fig wasp. Reaction products were visualized by ethidium bromide staining and UV illumination. Bands were the expected size based on the primer design. A no-template negative control ensured the specificity of the amplification. Actin was amplified from each sample as a control for RNA integrity. CsmOr2, Ceratosolen solmsi Or2; AbOr2, Apocrypta bakeri Or2; PpOr2, Philotrypesis pilosa Or2; PsOr2, Philotrypesis sp. Or2; A, antenna; T, thorax; L, leg; Abd, abdomen; H, head; Neg, negative control.

Table I: Synonymous and nonsynonymous divergence of Or2 genes in fig wasps.

\begin{tabular}{|c|c|c|c|c|c|c|c|c|c|c|c|}
\hline & C. sm & C. $c$ & A. bak & P. pil & P. sp. & N. vit & A. mel & A. aeg & C. qui & A. gam & D. mel \\
\hline C. $s m$ & & 0.0435 & 0.0546 & 0.0610 & 0.0608 & 0.0499 & 0.1864 & 0.3302 & 0.3064 & 0.3246 & I I I I \\
\hline C. $c$ & 0.6524 & & 0.0527 & 0.0514 & 0.0548 & 0.0462 & 0.1895 & 0.3285 & 0.2995 & 0.3214 & 0.3373 \\
\hline A. bak & $1.378 \mid$ & 1.3191 & & 0.0171 & 0.0181 & 0.0115 & 0.1755 & 0.3272 & 0.3025 & 0.3219 & 0.3398 \\
\hline P. pil & 1.3686 & I.1057 & 0.6505 & & 0.0090 & 0.0146 & 0.1797 & $0.335 I$ & 0.3094 & 0.3240 & 0.3443 \\
\hline P. sp. & 1.5050 & 1.0802 & 0.6121 & 0.0577 & & 0.0156 & 0.1835 & 0.3327 & 0.3043 & 0.3177 & 0.3416 \\
\hline N. vit & 1.5556 & 0.9242 & $0.668 I$ & 0.4286 & 0.3997 & & 0.1847 & 0.3349 & 0.3075 & 0.3248 & 0.3386 \\
\hline A. mel & 2.4788 & 1.6802 & 2.2714 & 1.7787 & 1.7499 & 1.9182 & & 0.3173 & 0.3196 & 0.3265 & 0.3206 \\
\hline A. aeg & 2.1785 & 1.5638 & $1.745 \mid$ & 1.4665 & I.4974 & 1.2952 & 1.8865 & & 0.0598 & 0.0802 & 0.1778 \\
\hline C. qui & n.a & 1.5110 & 1.6553 & 1.1044 & 1.0173 & 0.8283 & 1.7399 & 0.7988 & & 0.0750 & 0.1942 \\
\hline A. gam & 3.1533 & 1.3811 & 1.7594 & 1.2804 & 1.2362 & 1.0298 & 1.5609 & 0.9125 & 0.6374 & & 0.1737 \\
\hline D. mel & 2.5885 & 1.5277 & 1.4404 & 1.1202 & 1.0915 & 0.9476 & 1.6724 & 1.1165 & 0.7818 & 0.9111 & \\
\hline
\end{tabular}

Estimations of synonymous substitutions (Ks) according to Jukes and Cantor [135] are shown below the diagonal. The estimated nonsynonymous divergence $(\mathrm{Ka})$ according to Jukes and Cantor [135] are shown above the diagonal. n.a $=$ not applicable. Estimates in bold correspond to synonymous and nonsynonymous divergence between species of Diptera and fig wasp groups. Estimates in bold Italic correspond to synonymous and nonsynonymous divergence between $C$. solmsi and $C$. cornutus, and between $P$. pilosa and $P$. sp. Species names are as follows: $C$. sm, $C$ eratosolen solmsi;C. c, Ceratosolen cornutus;A. bak, Apocrypta bakeri;P. pil, Philotrypesis pilosa; P. sp., Philotrypesis sp.;N. vit, Nasonia vitripennis;A. mel, Apis mellifera;A. aeg, Aedes aegypti;C. qui, Culex quinquefasciatus;A. gam, Anopheles gambiae;D. mel, Drosophila melanogaster. 
solmsi and C. cornutus (Table 2). In contrast, these rates of substitutions were very similar between $P$. pilosa and $P$. sp. Significantly elevated substitution rates were not found when $C$. cornutus was compared with most of the NPFWs (except $P$. sp.). However, significantly elevated substitution rates were obtained when $C$. solmsi was compared with all NPFWs. No significant differences in the rate of nonsynonymous substitutions were detected between any lineages, although the number of substitutions at the 1st and 2 nd codon positions was higher in C. solmsi than in C. cornutus and NPFWs.

The extent of the non-random substitutions at synonymous codons in different species was measured by three algorithms (Table 3 ). Congruent with the rate of synonymous substitutions $(K s)$ being inversely related to codon usage bias $[71,72], C$. solmsi showed the lowest codon bias. The NPFWs exhibited a much higher codon bias. C. solmsi had the lowest $\mathrm{G}+\mathrm{C}$ content in their codons. Because the $\mathrm{G}+\mathrm{C}$ content at second codon positions was similar in all species, the lower $\mathrm{G}+\mathrm{C}$ content at (synonymous) third coding positions may have been the main cause of the lower codon bias of $C$. solmsi.

\section{Nucleotide diversity and neutrality tests for populations of fig wasps}

Sequences from the $\mathrm{N}$-terminal of the Or2 gene were collected from 20 individuals of each species in order to test the null hypotheses of strictly neutral evolution $[73,74]$. Following alignment, the 729 bp region revealed 18 haplotypes in C. solmsi [Accession numbers: FJ648225FJ648242], 13 haplotypes in A. bakeri [Accession numbers: FJ648208, FJ648210, FJ648212-FJ648222], 15 haplotypes in $P$. pilosa [Accession numbers: FJ648244, FJ648246, FJ648250-FJ648262] and 11 haplotypes in $P$. sp. [Accession numbers: FJ648265, FJ648267, FJ648269, FJ648275-FJ648282]. Increased numbers of segregating sites were observed in C. solmsi (28 sites) rather than in NPFWs (21 sites in A. bakeri, 23 sites in P. pilosa and 20 sites in $P$. sp.). Assuming a randomly mating population at equilibrium, the average number of pairwise nucleotide differences between sequences $(\pi)$ is expected to equal to average number of nucleotides segregating per site $(\theta)$. However, $\pi$ was always smaller than $\theta$ (Table 4 ) and, thus, negative values of Tajima's $D\left(D_{T}\right)$ [74], Fu and Li's $D^{*}$ $\left(D^{*}\right)$ and $F^{*}\left(F^{*}\right)[75]$ were observed for all populations of fig wasp.

For all sites of N-terminal, the majority of tests were significantly less than zero, suggesting a departure from neutrality [74]. There were two notable exceptions to the departure from neutrality. $D^{*}$ tests in $P$. pilosa and $P$. sp. did not indicate significant departure from neutrality, although both the values were close to significance. However, both $D_{T}$ and $F^{*}$ tests for the two species of Philotrypesis were significantly less than zero. Similar to tests of neutrality for all sites, most of tests for nonsynonymous sites significantly rejected the model of strict neutrality, suggesting selective forces. Unlike neutrality test for all sites and nonsynonymous sites, none of the tests of synonymous sites in the NPFWs Or2 data was significant; these data were consistent with a neutral model of evolution. However, significantly negative $D_{T}, D^{*}$ and $F^{*}$ tests were observed for synonymous sites of Or2 data in C. sol$m s i$, indicating too many rare nucleotide polymorphisms with respect to predictions of the neutral theory [76].

\section{Discussion}

\section{Identification of Or2 genes}

We identified $\mathrm{Or} 83 \mathrm{~b}$ orthologs for the first time and from four species of fig wasps associated with F. hispida. As expected, their primary aa sequences with the Or83b subfamily were highly conserved relative to other insects $[43,47-54]$. They had $>60 \%$ identity and $>72 \%$ similar-

Table 2: Results from Tajima's relative rate test for synonymous and nonsynonymous divergence of Or2 genes in fig wasps.

\begin{tabular}{|c|c|c|c|c|c|c|c|}
\hline \multirow[b]{2}{*}{ Outgroup } & \multirow[b]{2}{*}{ SpeciesA-Species B } & \multicolumn{3}{|c|}{ Substitutions at the $3 r d$ codon position } & \multicolumn{3}{|c|}{ Substitutions at the Ist and 2 nd codon positions } \\
\hline & & $\mathrm{Ma}$ & $\mathrm{Mb}$ & $\chi^{2}$ & $\mathrm{Na}$ & $\mathrm{Nb}$ & $\chi^{2}$ \\
\hline N. vit & P. pil- P. sp. & 13 & 7 & 1.80 & 3 & 4 & 0.14 \\
\hline \multirow[t]{2}{*}{ A. mel } & A. bak- P. pil & 52 & 44 & 0.67 & 9 & 8 & 0.06 \\
\hline & A. bak-P. sp. & 53 & 45 & 0.65 & 9 & 10 & 0.05 \\
\hline \multirow[t]{7}{*}{ D. mel } & C. c- A. bak & 73 & 72 & 0.01 & 19 & 17 & 0.01 \\
\hline & C. c- P. pil & 78 & 56 & 3.61 & 16 & 17 & 0.03 \\
\hline & C. c-P.sp. & 79 & 56 & $3.92 *$ & 18 & 16 & 0.12 \\
\hline & C. sm- C. c & 58 & 34 & $6.26 *$ & 20 & 12 & 2.00 \\
\hline & C. sm- A. bak & 85 & 60 & $4.31 *$ & 22 & 12 & 2.94 \\
\hline & C. sm- P. pil & 94 & 48 & $14.90 * * *$ & 22 & 15 & 1.32 \\
\hline & C. sm- P. sp. & 99 & 52 & 14.63 *** & 24 & 14 & 2.63 \\
\hline
\end{tabular}

$\mathrm{Ma}$ and $\mathrm{Mb}$ are the numbers of substitutions at the $3^{\text {rd }}$ codon positions in the lineages leading to species $\mathrm{A}$ and $\mathrm{B}$, respectively. $\mathrm{Na}$ and $\mathrm{Nb}$ are the number of substitutions at the Ist and 2 nd codon positions in the lineages leading to species $A$ and $B$, respectively. Species names are as in Table I. $P<0.05$ was used to reject the null hypothesis of equal rates between lineages. $* 0.05>P>0.01 ; * * 0.01>P>0.001 ; * * * P<0.001$. 
Table 3: Estimates of Codon Bias in Or2 genes of fig wasps.

\begin{tabular}{|c|c|c|c|c|c|c|}
\hline Taxa & ENC & $\mathrm{CBI}$ & Scaled $\chi^{2}$ & $\mathrm{G}+\mathrm{C} 2$ & $\mathrm{G}+\mathrm{C} 3 \mathrm{~s}$ & $\mathrm{G}+\mathrm{Cc}$ \\
\hline \multicolumn{7}{|c|}{ Fig wasps associated with F. hispida } \\
\hline C. $s m$ & 59.795 & 0.217 & 0.090 & 0.378 & 0.480 & 0.455 \\
\hline A. bak & 55.213 & 0.306 & 0.178 & 0.376 & 0.588 & 0.493 \\
\hline P. pil & 46.741 & 0.466 & 0.382 & 0.371 & 0.748 & 0.544 \\
\hline P. sp. & 45.124 & 0.498 & 0.413 & 0.371 & 0.769 & 0.549 \\
\hline \multicolumn{7}{|c|}{ Other hymenopteran species } \\
\hline N. vit & 42.120 & 0.573 & 0.511 & 0.374 & 0.816 & 0.565 \\
\hline A. mel & 58.591 & 0.236 & 0.123 & 0.367 & 0.594 & 0.483 \\
\hline \multicolumn{7}{|c|}{ Dipteran species } \\
\hline A. aeg & 50.176 & 0.347 & 0.309 & 0.370 & 0.656 & 0.511 \\
\hline C. qui & 34.475 & 0.666 & 0.870 & 0.387 & 0.876 & 0.594 \\
\hline A. gam & 42.589 & 0.508 & 0.472 & 0.391 & 0.768 & 0.557 \\
\hline D. mel & 37.994 & 0.608 & 0.647 & 0.374 & 0.820 & 0.558 \\
\hline
\end{tabular}

ENC, Effective Number of Codons. CBI, Codon Bias Index. SChi2, Scaled Chi Square. G+C2, G+C content at the second codon positions. $\mathrm{G}+\mathrm{C} 3 \mathrm{~s}, \mathrm{G}+\mathrm{C}$ content at (synonymous) the third codon position; i.e. the $\mathrm{G}+\mathrm{C}$ content in the third codon position excluding Trp and Met codons (nuclear universal genetic code). G+Cc, G+C content at codon positions. Species names are as in Table I.

ity, respectively, suggesting that the genes were orthologs in the different species. The extremely conservative C-terminal, especially at the last 164 aa, are involved in G-protein binding/activation required for downstream signal transduction [77]. The high identity and similarity of the aa sequences suggested that the four species of fig wasps are closely related species. This high degree of conservatism has not been observed in conventional ORs, even when compared to all 170 candidate ORs of Ap. mellifera [45], to 62 candidate ORs of D. melanogaster [44] and to 79 candidate ORs of An. gambiae [43]. This level of con-

Table 4: Neutrality tests for the Or2 gene of fig wasps using Tajima's $D$, Fu and Li's $D^{*}$ and $F^{*}$ statistics.

\begin{tabular}{|c|c|c|c|c|c|}
\hline Sample & $\pi(\%)$ & $\theta(\%)$ & $D_{T}$ & $D^{*}$ & $F^{*}$ \\
\hline \multicolumn{6}{|l|}{ all sites } \\
\hline C. $s m$ & 0.396 & 1.083 & $-2.473^{* * * *}$ & $-3.700 * *$ & $-3.883 * *$ \\
\hline A. bak & 0.349 & 0.812 & $-2.257^{* *}$ & $-2.815^{*}$ & $-3.082 * *$ \\
\hline P. pil & 0.456 & 0.889 & $-1.872^{*}$ & $-2.40 \mathrm{I}$ & $-2.611 *$ \\
\hline P. sp. & 0.357 & 0.773 & $-2.044^{*}$ & -2.418 & $-2.683 *$ \\
\hline \multicolumn{6}{|c|}{ Nonsynonymous sites } \\
\hline C. sm & $0.45 \mathrm{I}$ & 1.218 & $-2.405^{* *}$ & $-3.519 * *$ & $-3.710 * *$ \\
\hline A. bak & 0.366 & 0.928 & $-2.25 I^{* *}$ & $-2.989 * *$ & $-3.221^{* *}$ \\
\hline P. pil & 0.460 & 1.044 & $-2.104^{*}$ & $-2.530 *$ & $-2.794 *$ \\
\hline P. sp. & 0.474 & 0.986 & $-1.94 I^{*}$ & -2.134 & -2.413 \\
\hline \multicolumn{6}{|c|}{ Synonymous sites } \\
\hline C. $s m$ & 0.288 & 0.812 & $-2.121^{*}$ & $-3.08 I^{* *}$ & $-3.247 * *$ \\
\hline A. bak & 0.316 & 0.580 & -1.739 & -1.557 & -1.857 \\
\hline P. pil & 0.448 & 0.580 & -0.694 & -1.213 & -1.232 \\
\hline P. sp. & 0.123 & 0.348 & -1.723 & -2.386 & -2.535 \\
\hline
\end{tabular}

$\pi$, the average number of nucleotide differences per site between sequences; $\theta$, average number of nucleotides segregating per site; $D_{T}$, Tajima's $D$ value; $D^{*}$, Fu and Li's $D^{*}$ value; $F^{*}$, Fu and Li's $F^{*}$ value. Species names are as in Table I. $* 0.05>P>0.02$; $* * 0.02>P>0.001$; $* * * * 00.001$. servatism reflected a strong selective pressure on the aa sequence and was consistent with the important role of non-conventional receptors in the olfactory process [42]. The aa sequences of the four fig wasps included all the seven transmembrane domains of the G-protein coupled receptor. The group of threonines and tyrosines were extremely conserved (aa 465 and 466) in the region of TM 7 (Figure 1). They constituted candidate phosphorylation sites that may be important for regulating protein function [78]. An unusually long second intracellular loop was detected between TM 4 and TM 5. The function of this structural specialization remained unknown, even though the second extracellular loop of certain types of mammalian G protein-coupled receptors may be critical for ligand binding and affinity $[79,80]$. Recent bioinformatics and experimental investigations revealed that the membrane topology of ORs in Drosophila was, in fact, the inverse of mammalian GPCRs, with the N-terminal of these receptors located intracellularly $[56,63]$. Thus, we speculate that the long second intracellular loop of the non-conventional receptor in insects likely plays an important role in binding conventional ligand-binding ORs.

\section{Adaptation of spatial expression patterns of Or2 genes}

We characterized the spatial expression patterns of Or2 genes in four species of fig wasp. RT-PCR experiments demonstrated that receptors were expressed only in adult male heads (including antennae and maxillary palps), but more widely in various tissues from adult females, including the antennae, legs and abdomens. The current view is that $\mathrm{Or} 83 \mathrm{~b}$ gene does not directly bind odorant ligands but rather it acts to form heterodimers with conventional ORs; this ensures appropriate dendritic localization and function [55-57]. The broad spatial expression patterns in OSNs further support the essential role of Or83b orthologs for a sense of smell $[52,55]$. Given the different habits of female and male fig wasps, the sex-tissue-specific expression of Or2-type receptors may indicate a role in host searching and oviposition in adult females.

Host plants are distributed patchily. Therefore, adult females must be able to distinguish the particular odours emitted by their host plant from the myriad of other volatile compounds. Such remarkable sensitivity and specificity is likely achieved by ORs expressed in the legs of adult female fig wasps. Likewise, Or83b orthologs are also expressed in legs of An. gambiae and Ae. Aegypti. Mosquito legs are known only as having a gustatory function $[50,53]$. Gustatory receptors (GRs) are the only chemosensory receptors whose expression has been detected in the legs of $D$. melanogaster $[81,82]$, the location of gustatory sensilla. It seems likely that in addition to their olfactory function, Or $83 \mathrm{~b}$ orthologs in legs of fig wasps might function in a contact chemosensory pathway. Because they function in heterodimerization, perhaps Or83b 
orthologs are required in both olfactory and gustatory process. Chemosensory responses derived from legs would be extremely close to volatiles of fig fruit. These receptors in legs may play a critical role in evaluating the status of a host plant when fig wasps land for oviposition.

Lower levels of expression were detected in the abdomens of females in four species of fig wasp. Thus, the female's abdomen likely plays a critical role in locating an oviposition site. A small number of sensillae occur on the vaginal plate of the abdomen in $D$. melanogaster, suggesting a function in oviposition site selection in fruit flies [83]. In contrast to Or2 in the fig wasp, expression patterns of Or $83 b$ orthologs have not been discovered in the abdomens of other insects, including D. melanogaster (DOr83b) [47-49], An. gambiae (AgOR7) [50], H. virescens (HvirR2) [51], Ap. mellifera (AmelR2) [52] and Ae. aegypti (AaOR7) [53]. In the fig wasps, this pattern likely reflects an adaptive genetic change in response to their host. Both female PFWs and NPFWs use their ovipositor to touch fig inflorescences and for oviposition [37-39]. Chemosensory function in the abdomen of fig wasp may occur as described for the expression of $A g O R 7$ in the proboscis and labellum of An. gambiae [50]. Abdominal chemoreception in all female fig wasps may function in both olfaction and gustation [84].

Support for the adaptation hypothesis is obtained from the males of all fig wasp species. Wingless male fig wasps usually live in the fig throughout their life. They do not need to search for a host. Mating is their primary task. Male fig wasps have highly specialized mouth parts for pulling females out of their galls, and, most importantly, for chewing an exit tunnel for newly transformed female wasps to leave the syconium [85-87]. In the male's enclosed environment, the broad expression of ORs may not be required. Thus, it is not surprising that female wasps express ORs in a greater number of tissues than do male wasps. In support of this hypothesis, few sensory hairs occur on a male's body.

We can not exclude the possibility that several conventional ORs independently express in some OSNs of other tissues, beside the head of males. Or $83 b$ orthologs do not always co-express with conventional ORs in all OSNs [4850]. Indeed, the lack of $A g O R 7$ (mosquito orthologs) expression in grooved peg sensillum of An. gambiae suggests the presence of an alternative pathway for olfactory signal transduction that is independent of $O R 7$ function [50]. Unexpectedly, a weak band was obtained with cDNA prepared from the thorax of C. solmsi. Most NPFWs oviposit into ovaries of female flowers by inserting their ovipositor through the syconium wall (while not entering the syconium) [37-39]. Unlike NPFWs, female PFWs penetrate into the fig cavity through the ostiolar bracts and ovi- posit in the ovaries of the female flowers. In doing so, a PFW pollinates female flowers. Different oviposition behaviour of PFWs and NPFWs may cause different tissuespecific expression. In the process of entering the syconium's ostiole, the antennae of female PFWs are easily broken off. Expression of $\mathrm{Or} 2$ in the thorax and other tissues may help a pollinator to accurately locate oviposition sites in the dark inner syconium. PFWs seem to have less time to search for hosts because adult PFWs live for a much shorter period of time (from a few hours to 2 days) than do adult NPFWs (several days to 2 weeks) (personal observation). Thus, unlike NPFWs, PFWs may require a broad tissue expression of $\mathrm{Or} 2$, in part for increased sensitivity.

Tissue-specific gene expression implies that fig wasps may have cryptic olfactory inputs in tissues that express ORs. If the leg and/or abdomen of a fig wasp functions in olfaction, it is likely to be an exaptation [88]. The primary function of legs and the abdomen are movement and reproduction, respectively. The role of olfaction in these organs is a secondary function. The diversity of expression patterns may be important for determining species-specific olfactory profiles, such as in the detection of fruit odours by fruit flies [62] and human host odours by mosquitoes $[50,53]$. The patterns in fig wasps may reflect species-specific adaptations to ecology, habitat and physiology. Further study into the function and characteristics of Or2 and other conventional ORs will facilitate our understanding of co-evolution in this model system.

\section{Strong purifying selection for most orthologous amino acids}

The evaluation of selection pressure used the $\mathrm{Ka} / \mathrm{Ks}$ ratio, based on 19 orthologous Or2 genes. A very low average $\mathrm{Ka} / \mathrm{Ks}$ ratio indicated that $\mathrm{Or} 2$ genes were mainly subjected to purifying pressure. This finding differed drastically from the properties of the ORs family, most often characterized by rapid evolution and highly species-specific gene repertoires $[44,45,62]$. A higher level of functional constraint on protein-coding exon sequences should lead to lower level of nonsynonymous variation which usually generates low average nonsynonymous:synonymous substitution ratios. Thus, the low average $K a / K s$ ratio suggests that the Or2-type receptor plays an important role in the olfactory process of insects and is subject to a higher level of functional constraint. The 21st aa of Or2 appeared to be subjected to positive selection, although the $P$-value was not very significant. The aa in PFWs (S) differed from that in all NPFWs (G). Suzuki and Gojobori (1999) demonstrated that two amino acid sites of the human leukocyte antigen (HLA) gene undergoing positive selection might be involved in antigen recognition [89]. Other studies also showed that positive selection is focused mainly on the binding site and the distinct 
DNA-binding properties are determined by one or a few critical amino acids [90-94]. If the 21st aa performed a binding function, such divergence could have reflected ligand binding specificity between PFWs and NPFWs. Species-specific adaptive divergence might have been driven by the environment of the host [62]. Ecological niches differ between PFWs and NPFWs [37-39]. The composition and concentration of bouquets could vary between the inside and outside the syconium, although no data document this to occur. PFWs that enter the syconium are likely to smell extra syconian odours. Perhaps the change of aa at site 21 helped the Or 2 of pollinators bind conventional ORs that respond to odours in the syconium.

\section{Elevated rate of substitution in pollinators}

All PFWs and most NPFWs are currently classified as being part of the same chalcid family, Agaonidae [95-97]. However, recent molecular studies suggest that this family is paraphyletic and all PFWs form a monophyletic group $[17,98]$. An evaluation of closely related species should help to control for possible differences in mutation rate $[69,99]$. Thus, sequence data for Or2 genes were also collected from C. cornutus, a pollinator of $F$. auriculata and closely related to C. solmsi, to increase the power of our analysis of substitution rates.

Between-species comparisons of substitution rates involved two species of PFWs and three NPFWs. An elevated substitution rate was not detected in Philotrypesis, but it was in C. solmsi. The rapid evolution of Or2 genes in C. solmsi became more apparent when the closely related species in the genus Ceratosolen were compared. Low effective population sizes may be accompanied by relatively weak selection compared to drift yet usually drive an increase in the frequency of slightly deleterious substitutions [62,100-102]. However, no evidence suggests that PFWs have smaller population sizes than NPFWs. Typically, pollinators are almost always the dominant wasp (Herre EA \& Machado CA, personal communication), though NPFWs might affect pollinator numbers by successfully invading the fig-pollinator mutualism system [103]. Thus, the hypothesis of a low effective population size can not be employed to explain these observations. Machado [104] found that species of Ceratosolen exhibited accelerated mutation in their mitochondrial genome relative to species in other genera. It is possible that this increased rate has affected the nuclear genome as well through cytonuclear associations [105-108]. For example, Rand et al. (2004) demonstrated that the association between nuclear and mitochondrial substitutions drives the evolutionary divergence [105]. Mishamar et al. (2006) showed that mitochondrial DNA and nuclear DNA complex I genes may have co-evolved [109].

Our results are consistent with the proposal that the rate of synonymous substitutions is inversely related to codon usage bias $[71,72]$. Codon usage bias was much lower in C. solmsi than in the NPFWs. The changed codon bias indicated that mutations were not strictly neutral $[101,110]$. Weak selection on synonymous mutations caused a codon usage bias in bacteria, yeast and flies [111113]. In Drosophila, preferred codons also correspond to the more abundant tRNAs [114,115]. Because the most abundant tRNA translates their corresponding codon more rapidly, the preferred codon speeds up translation $[116,117]$. However, there are many counterexamples of highly expressed genes with little or no codon bias $[118,119]$. Therefore, we cannot unequivocally state that Or2 genes in PFWs that have lower codon usage bias are expressed at a lower level than in NPFWs. Conversely, the broader tissue expression of Or2 in PFWs than in NPFWs, together with the higher degree of host specificity of PFWs than NPFWS [13,18-23], implies that Or2 genes in PFWs are expected to be expressed at a higher level than in NPFWs.

\section{Non-neutral patterns of nucleotide variation}

Olfaction genes of insects are widely assumed to experience selection [43,45,62,120-122]. Our investigation of Or2 polymorphism in four species of fig wasp sought evidence for selection, and the signature of selection can be detected by various tests $[74,75,123]$. These tests also tend to implicate the corresponding evolutionary forces. The significantly negative $D_{T}$ and $F^{*}$ values for Or2 data from populations of C. solmsi, A. bakeri, P. pilosa and P. sp. indicate a higher-than-expected number of low-frequency variations. This is consistent with purifying selection or directional selection reducing deleterious mutations in Or2 genes [74]. Once deleterious mutations appear in population, they will be maintained at a relatively low frequency due to selection pressures. And low-frequency variation will be increased more than in neutral conditions. For the DNA data, $\theta$ will be increased, and the test value will be significantly negative. With $D^{*}$, Or2 data from $C$. solmsi and $A$. bakeri reject the neutrality hypothesis, while those from $P$. pilosa and $P$. sp. do not, although the values are close to significance $(0.10>P>0.05)$ [75]. This result likely reflects either short length of sequence or a small sample size [124]. Increasing the length of the sequence and/or sample size could yield a more accurate result. Because both the $D_{T}$ and $F^{*}$ tests support a non-neutral model of evolution, most likely the Or2 data in P. pilosa and $P$. sp. also reflect selection.

Most tests on nonsynonymous sites of Or2 also show a significantly negative departure from neutrality, again suggesting possible purifying selection. Certainly, Or2 plays an important role in fig wasps and variations on nonsynonymous sites are maintained at a relatively low proportion. An alternative explanation for negative test values is the occurrence of directional selection. It eliminates deleterious mutations from the population and pro- 
motes the fixation of advantageous mutations that optimize function and lead to adaptation to an ecological niche. The $D_{T}$ test, together with $D^{*}$ and $F^{*}$ tests, clearly rejects the null hypothesis that the synonymoussites of Or2 gene in C. solmsi are evolving under a strictly neutral model of molecular evolution [74]. Selection pressures seem to also act against slightly deleterious mutations at synonymous sites within C. solmsi. Regarding synonymous sites in NPFWs, none of tests significantly rejected the null hypothesis. Thus, these data are consistent with a neutral model of evolution $[74,75]$.

The use of several tests appears to be a more powerful means of inferring patterns of selection affecting nucleotide variance. Combined with test results on nonsynonymous sites, Or2 in C. solmsi appears to experience more effective selection relative to that of NPFWs. This might be related to the greater host specificity of PFWs relative to NPFWs, and/or it may also be related to the larger effective population size of PFWs. It remains to be determined whether this trend occurs just for Or2 or throughout the entire genome of $C$. solmsi. Data from additional loci are required to evaluate this possibility.

\section{Conclusion}

Or83b orthologous genes obtained from one pollinator and three non-pollinator species of fig wasps associated with F. hispida were evaluated. We examined spatial expression patterns, evolutionary rate and selective forces acting on these genes in fig wasps.

Or2 genes were expressed beyond the known primary olfactory tissues and potentially this has functional implications [52]. Or2 plays an essential role in the localization and function of co-expressed OR proteins [55,57]. Thus, the expressions of $\mathrm{Or} 2$ genes in non-olfactory tissues of female fig wasps strongly indicated the presence of cryptic olfactory inputs in these tissues. Olfactory responses obtained from non-olfactory tissues may have indicated a long-term adaptation to figs. Future investigations can determine whether these genes have a chemosensory function expressed in non-olfactory tissues, or not.

Our results, taken together with those from previous studies [17], suggested that an accelerated rate of substitution was likely characteristic of the Or2 gene in C.solmsi, unlike that in NPFWs associated with F. hispida. Neutrality tests indicated that $\mathrm{Or} 2$ genes in most fig wasp populations were not concordant with the hypothesis of neutral selection. Considering the importance of Or2, selection against deleterious mutations could have maintained variations at a relatively low proportion. Unlike NPFWs, selection pressures were also detected in synonymous sites within C.solmsi, suggesting a more effective role on a pollinator species that is more specific to fig host.

\section{Methods \\ Taxa sampling}

Four species of fig wasp (C. solmsi, A. bakeri, P. pilosa and $P$. sp.) were randomly collected from fruits of $F$. hispida in Danzhou, Hainan province, China. The species, C. cornutus from F. auriculata, was collected for comparative analyses. Mature figs, from which the fig wasps emerge, were collected by Haoyuan $\mathrm{Hu}$ and Liming Niu, and dissected in the lab. All emerged fig wasps were immediately preserved in Sample Protector (TaKaRa). The four species were identified and then maintained at $-80^{\circ} \mathrm{C}$.

\section{Cloning the Or83b orthologous gene}

Total RNA was isolated by using TRIzol procedures according to the manufacturer's instructions (Transgen Biotech). Each experiment used about $3 \mu \mathrm{g}$ RNA for firststrand cDNA synthesis with EasyScript Reverse Transcriptase (Transgen Biotech) and Oligo $(\mathrm{dT})_{18}$ primers (Invitrogen) to generate templates for individual PCR reactions. Seven degenerate primers were designed according to amino acid sequences retrieved from GenBank: Nasonia vitripennis isoform 1 [GenBank: $\underline{\mathrm{XM} \text { 001607869] }}$ Apis mellifera R2 [GenBank: XM_001121145], Drosophila melanogaster Or83b [GenBank: NM079511], Anopheles gambiae Or7 [GenBank: AY363725], Culex quinquefasciatus Or7 [GenBank: DQ231246], Bombyx mori R2 [GenBank: AJ555487].

A short length of conserved C-terminal coding region (735 bp) was initially amplified using three degenerate primers: FW5'1: 5'-GYTNATHTTYGCNTGYGARC-3'; FW5'2: 5'-AAGGGCATCATGAAGCCCYTNATGGARYT-3'; FW3'1: 5'-TTACTTCAGCTGCACCARNACCATRAA-3'. FW5'2 and FW3'1 were designed using CODEHOP http:/ /blocks.fhcrc.org/blocks/codehop.html.

Based on the initial results, four additional degenerate primers were designed and used to obtain the remaining N-terminal coding region sequences: FW5'3: 5'-ATGATGAARWYNAAGCAWCARGG-3'; FW3'3: 5'-TTGCTRTADATNCCWCGNASRTC-3'; FW5'4: 5'ATGAARWYNAAGCAWCARGGNYTRRTNGCSGA-3'; FW3'4: 5'TGRTCNGCRCTKCCRGCCTTGAA-3'. A reaction volume of $50 \mu \mathrm{l}$ contained $2 \mathrm{mM} \mathrm{MgCl}_{2}, 0.2 \mathrm{mM}$ of each dNTP, $0.2 \mu \mathrm{M}$ of each primer, and $2.5 \mathrm{U}$ of EasyTaq DNA polymerase (TransGen Biotech). PCR program involved $5 \mathrm{~min}$ at $94^{\circ} \mathrm{C}$, then 35 cycles with $94^{\circ} \mathrm{C}$ for 30 $\mathrm{s}, 52^{\circ} \mathrm{C}$ for $40 \mathrm{~s}$ and $72^{\circ} \mathrm{C}$ for $1 \mathrm{~min}$, followed by incubation for $10 \mathrm{~min}$ at $72^{\circ} \mathrm{C}$. The amplified DNA products were purified and automated DNA sequencing was performed on an ABI3730 with an ABI PRISM BigDye terminator cycle sequencing ready reaction kit (Perkin-Elmer Biosystems). The same $\mathrm{N}$-terminal data were obtained from 20 individuals per species of PFWs and NPFWs associated with F. hispida. These taxa were randomly collected 
from different trees and different crops. Thus, we were able to assess levels of intraspecific variation and test the neutrality model. Sequences from N-terminal and C-terminal were assembled as contiguous fragments using ContigExpress of Vector NTI Advance 9 (Invitrogen). The four full-length sequences of Or83b orthologous genes were obtained from four species of wasps associated with $F$. hispida. We also obtained a full-length sequence from $C$. cornutus. Thus, we were able to compare substitution rates in closely related species. The TMHMM v2.0 http:// www.cbs.dtu.dk/services/TMHMM/ program [125,126] was used to predict the transmembrane domain (TM; Figure 1).

\section{Sequence alignment}

Primary amino acid sequences of four species of fig wasp associated with $F$. hispida and 15 additional insect species were obtained from GenBank (accession numbers indicated in brackets): Microplitis mediator Or1 [EF141511], Nasonia vitripennis isoform 1 [XM_001607869], Apis mellifera $R 2$ [XX 001121145], Drosophila melanogaster Or83b [NM079511], Ceratitis capitata R2 AY843206], Anopheles gambiae Or7 [AY363725], Culex quinquefasciatus Or7 [DQ231246], Aedes aegypti Or7 [AY582943], Bombyx mori Or2 [AJ555487], Antheraea pernyi Or2 [AJ555486], Helicoverpa zea R2 [AY843204], Mamestra brassicae R2 [AY485222], Spodoptera exigua R2 [ㅅ862142], S. litura R2 [DQ845292] and Tribolium castaneum R2 [XX 968103]. Sequences were aligned by using CLUSTAL W [127] with default multiple alignment parameters. The alignment was optimized manually, and gap positions present in > $70 \%$ of the sequences were deleted. Sequence logos (Figure 1) were generated using Weblogo http://weblogo.ber keley.edu/logo.cgi $[128,129]$. Both the identity and similarity values from all the possible comparisons were obtained using the EMBOSS Pairwise Alignment Algorithm http://www.ebi.ac.uk/emboss/align/.

\section{Phylogenetic analyses}

Sequences having heterogeneous patterns of nucleotide or amino acid substitution may form erroneous branching patterns [130]. Therefore, we employed the Disparity Index Test [131] as implemented in MEGA 4.0 [132] to test 1 st +2 nd codon positions, 3rd codon positions and the amino acid sequences for composition homogeneity among lineages. A Monte Carlo test (1000 replicates) was used to estimate the $P$-values [131]. A significantly heterogeneous pattern was detected at $3 \mathrm{rd}$ codon positions in most comparisons $(P<0.05)$. In contrast to 3rd codon position, the 1 st +2 nd nucleotide positions and the amino acid sequences were found to be more homogeneous, except for 1 st +2 nd codon position of C. capitata (data not show). Therefore, we used the $1 \mathrm{st}+2 \mathrm{nd}$ codon positions and the amino acid sequences in the phylogenetic analysis. All positions containing gaps and missing data were eliminated from the dataset (complete deletion option). The final dataset here contained 864 aligned nucleotide positions and 430 aligned amino acid positions. The best tree was selected using the maximum parsimony (MP) criterion. Nodal stability was assessed using bootstrap proportions (1000 replicates) and the values are shown next to the branches. The MP trees were obtained using the Close-Neighbour-Interchange algorithm with search level 3, in which the initial trees were obtained with the random addition of sequences (10 replicates). Phylogenetic analyses were conducted in MEGA 4.0 [132] and PAUP* 4.0b10 [64].

\section{RNA expression}

Antennae, thoraxes, abdomens, legs and heads (male) of four species of fig wasp associated with $F$. hispida were dissected in Sample Protector (TaKaRa), and total RNA of each tissue was isolated by using TRIzol procedures according to the manufacturer's instructions (Transgen Biotech). A series of non-quantitative RT-PCR experiments were performed by using cDNA preparations from various tissues of all male or female fig wasps and the same primer pairs were used for each type of tissue. In order to control for genomic DNA contamination, primers spanning predicted introns were designed for subsequence NEST-PCR reactions: FW5'5: 5'AGTGCBATCAARTAYTGGGTNGA-3'; FW5'6: 5'-CTNGCNTACCARGCNAC NAA-3'; FW3'5: 5'-TTACTTCAGCTGCACCARN ACCATRAA-3'. All RT-PCR reactions were replicated at least three times. We also amplified the actin gene [133] from each tissue as a control for cDNA integrity by use of the following primers: $\beta$-actin $\mathrm{F}$ : 5 '-ATGTGCAAGGCHGGHTTCGC-3'; $\beta$-actin R: 5 'CRTGGATRCCGCA VGAYTCC-3'. PCR products were purified and directly sequenced as described above.

\section{Selective pressure on individual codons}

Selective pressure (positive selection and purifying selection) on individual codons (sites) within the coding region of the 19 amino acid sequences of Or $83 b$ orthologs were inferred using the Single Likelihood Ancestor Counting (SLAC) package http://www.datamonkey.org[89]. This codon-based maximum likelihood method did not assume equal synonymous substitution rates throughout the sequence and it chose the most appropriate model for nucleotide substitution.

\section{Substitution rate}

Evolutionary divergence at the gene-coding region was estimated by the number of synonymous substitutions per synonymous site $(K s)$ and the number of nonsynonymous substitutions per nonsynonymous site ( $\mathrm{Ka}$ ) [68]. Analyses were conducted using the modified Nei-Gojobori (Jukes-Cantor) method (assumed transition/transversion bias $=1.021)$ in MEGA4 $[132,134,135]$. The 
results were based on the sequences alignment of seven hymenopteran species (C. solmsi, C. cornutus, A. bakeri, P. pilosa, P. sp., N. vitripennisl and Ap. mellifera) and four dipteran species (Ae. aegypti, C. quinquefasciatus, An. gambiae and D. melanogaster). All positions containing alignment gaps and missing data were eliminated only in pairwise sequence comparisons (pairwise deletion option).

Equality of evolutionary rate between two lineages of fig wasps was tested using an outgroup in Tajima's relative rate test in MEGA4 [70,132].P $<0.05$ was used to reject the null hypothesis of equal rates between lineages.

Effective Number of Codons (ENC) [136], Codon Bias Index (CBI) [137] and Scaled Chi-square (SChi2) [113] methods were implemented in DnaSP program version 4.50.3 [138]. These methods estimated the codon bias present at the gene-coding region. The value of ENC ranges from 20 (only one codon is used for each amino acid; i.e., the codon bias is maximum) to 61 (all synonymous codons for each amino acid are equally used; i.e., no codon bias). CBI values range from 0 (uniform use of synonymous codons) to 1 (maximum codon bias). SChi2 measured the difference between the observed number of codons and those expected from equal usage of codons. A higher SChi2 value indicated a stronger deviation from the random use of synonymous codons.

\section{Neutrality test}

The signature of selection can be detected by various tests $[74,75,123]$, but it is not clear which is most powerful. Thus, we exploited Tajima's $D$ statistic [74], and $\mathrm{Fu}$ and Li's $D^{*}$ and $F^{*}$ tests [75] to estimate deviations from neutral expectations. These tests were implemented in DnaSP version 4.50.3 [138]. A negative Tajima's $D$ signified an excess of low frequency polymorphisms, indicating population size expansion, purifying selection, recent directional selection and/or background selection of deleterious mutation. A positive Tajima's $D$ signified low levels of both low and high frequency polymorphisms, indicating a decrease in population size and/or balancing selection [74]. The same thing held for Fu and Li's tests.

\section{Authors' contributions}

BL carried out the majority of the molecular work, designed and conceived the study and drafted the manuscript. NW designed some primers and carried out a portion of the molecular work. JX participated in the design of the study. YX coordinated the study. RWM contributed to data analysis, interpretations of phylogenetic inference and participated in the writing. DH participated in the design of the study, directed the research and helped to draft the manuscript. All authors read and approved the final manuscript.

\section{Acknowledgements}

We thank two reviewers for many useful comments. We also thank Jinzhong Fu, Carlos A. Machado and Xiaomao Zeng for helpful comments and valuable discussion on earlier versions of this manuscript. This project was supported by the National Natural Science Foundation of China (NSFC grant no. 30770302, 30570970) and the Program of Ministry of Science and Technology of the People's Republic of China (2006FYI I0500), partially by National Science Fund for Fostering Talents in Basic Research (NSFCJ0630964/J0109).

\section{References}

I. Gomulkiewicz R, Nuismer SL, Thompson JN: Coevolution in variable mutualisms. Am Nat 2003, I 62(Suppl 4):S80-S93.

2. Wiebes JT: Co-evolution of figs and their insect pollinators. Annu Rev Ecol S 1979, 10:1-12.

3. Thompson JN: Coevolution and alternative hypotheses on insect/plant interactions. Ecology 1988, 69(4):893-895.

4. Rasplus JY: The one-to-one species specificity of the FicusAgaoninae mutualism: how casual? In The Biodiversity of African plants Edited by: van der Maesen LJ, van der Burgt XM, van Medenbach de Rooy JM. Dordrecht: Kluwer Academic Publishers; 1996:639-649.

5. Michaloud G, Carriere S, Kobbi M: Exceptions to the one: one relationship between African fig trees and their fig wasp pollinators: Possible evolutionary scenarios. J Biogeogr 1996, 23(4):5 I3-520.

6. Ramírez BW: Host specificity of fig wasps (Agaonidae). Evolution 1970, 24(4):680-691.

7. Kato M, Takimura A, Kawakita A: An obligate pollination mutualism and reciprocal diversification in the tree genus Glochidion (Euphorbiaceae). Proc Natl Acad Sci USA 2003, I00(9):5264-5267.

8. Ware $A B$, Compton SG: Breakdown of pollinator specificity in an African fig tree. Biotropica 1992, 24(4):544-549.

9. Kerdelhue C, Hochberg ME, Rasplus JY: Active pollination of Ficus sur by two sympatric fig wasp species in West Africa. Biotropica 1997, 29(1):69-75.

10. Molbo D, Machado CA, Sevenster JG, Keller L, Herre EA: Cryptic species of fig-pollinating wasps: Implications for the evolution of the fig-wasp mutualism, sex allocation, and precision of adaptation. Proc Natl Acad Sci USA 2003, I 00( I 0):5867-5872.

II. Machado CA, Robbins N, Gilbert MTP, Herre EA: Critical review of host specificity and its coevolutionary implications in the fig/fig-wasp mutualism. Proc Natl Acad Sci USA 2005, I 02(suppl_I):6558-6565.

12. Jackson AP, Machado CA, Robbins N, Herre EA: Multi-locus phylogenetic analysis of Neotropical figs does not support cospeciation with the pollinators: The importance of systematic scale in fig/wasp cophylogenetic studies. Symbiosis 2008 , 45:57-72.

13. Herre EA, Jander KC, Machado CA: Evolutionary ecology of figs and their associates: Recent progress and outstanding puzzles. Annu Rev Ecol Evol S 2008, 39(1):439-458.

14. Ramírez BW: Coevolution of Ficus and Agaonidae. Ann Mo Bot Gard 1974, 6 I (3):770-780.

15. Galil J: Fig biology. Endeavour 1977, I:52-56.

16. Herre EA: Coevolution of reproductive characteristics in 12 species of New World figs and their pollinator wasps. Experientia 1989, 45(7):637-646.

17. Machado CA, Herre EA, McCafferty SS, Bermingham E: Molecular phylogenies of fig pollination and non-pollinating wasps and the implications for the origin and evolution of the fig-fig wasp mutualism. J Biogeogr 1996, 23(4):53 I-542.

18. Gordh G: The comparative external morphology and systematics of the neotropical parasitic fig wasp genus Idarnes (Hymenoptera: Torymidae). Univ Kansas Sci Bull 1975, 50(9):389-455

19. Bouček Z, Watsham A, Wiebes JT: The fig wasp fauna of the receptacles of Ficus thonningii (Hymenoptera, Chalcidoidea). Tijdschr Entomol I98I, I 24(5): |49-233.

20. Ulenberg SA: The phylogeny of the genus Apocrypta Coquerel in relation to its hosts Ceratoselen Mayr (Agaonidae) and Ficus L. K Ned Akad Wet Verh Afd Natuurk D Tweed Reeks 1985, 83:149-176. 
21. Compton SG, Holton KC, Rashbrook VK, Van Noort S, Vincent SL, Ware AB: Studies of Ceratosolen galili, a non-pollinating agaonid fig wasp. Biotropica I991, 23(2): 188-194.

22. Weiblen GD, Bush GL: Speciation in fig pollinators and parasites. Mol Ecol 2002, I I(8): I573-I578

23. Marussich WA, Machado CA: Host-specificity and coevolution among pollinating and nonpollinating New World fig wasps. Mol Ecol 2007, I 6(9): 1925-1946.

24. Takken W, Knols BG]: Odor-mediated behavior of Afrotropical malaria mosquitoes. Annu Rev Entomol I999, 44(I): I 3 I-I57.

25. Hildebrand JG, Shepherd GM: Mechanisms of olfactory discrimination: Converging evidence for common principles across phyla. Annu Rev Neurosci 1997, 20(I):595-63I.

26. Krieger J, Breer $\mathrm{H}$ : Olfactory reception in invertebrates. Science 1999, 286(5440):720-723.

27. Van Noort S, Ware AB, Compton SG: Pollinator-specific volatile attractants released from the figs of Ficus burtt-davyi. S Afr J Sci 1989, 85:323-324.

28. Ware AB, Kaye PT, Compton SG, van Noort S: Fig volatiles: their role in attracting pollinators and maintaining pollinator specificity. Plant Syst Evol 1993, I 86:147-156.

29. Hossaert-Mckey M, Gibernau M, Frey JE: Chemosensory attraction of fig wasps to substances produced by receptive figs. Entomol Exp Appl 1994, 70(2): |85-191.

30. Ware $A B$, Compton SG: Dispersal of adult female fig wasps: I. Arrivals and departures. Entomol Exp Appl I 994, 73(3):221-229.

31. Ware $A B$, Compton SG: Dispersal of adult female fig wasps: 2. Movements between trees. Entomol Exp Appl 1994 73(3):23I-238.

32. Grison-Pige L, Bessiere J-M, Hossaert-Mckey M: Specific attraction of fig-pollinating wasps: role of volatile compounds released by tropical figs. J Chem Ecol 2002, 28(2):283-295.

33. Berg CC: Reproduction and evolution in Ficus (Moraceae): traits connected with the adequate rearing of pollinators. Mem New York Bot Gard 1990, 55: I69- I85.

34. Van Noort S, Compton SG: Convergent evolution of agaonine and sycoecine (Agaonidae, Chalcidoidea) head shape in response to the constraints of host fig morphology. J Biogeogr 1996, 23(4):415-424.

35. Frank SA: The behavior and morphology of the fig wasps Pegoscapus assuetus and $P$. jimenezi: Descriptions and suggested behavioral characters for phylogenetic studies. Psyche (Cambridge, Massachusetts) 1984, 9 I(3-4):3-4.

36. Murray MG: Comaparative morphology and mate competition of flightless male fig wasps. Anim Behav 1990, 39(3):434-443.

37. Abdurahiman UC, Joseph $\mathrm{KJ}$ : Observation on the oviposition behaviour in Apocrypta bakeri Joseph (Torymidae: Hymenoptera). J Bombay Natur Hist Soc 1979, 76(2):219-223.

38. Abdurahiman UC: Observations on the oviposition behaviour in Philotrypesis pilosa Mayr (Torymidae: Hymenoptera). Proc Symp Environ Biol Trivandrum 1980, I977:146-I50.

39. Ansari $\mathrm{MH}$ : The process of egg laying in Idarninae (Chalcidoidea: Hymenoptera). Indian J Entomol 1967, 29(4):380-384.

40. Hamilton WD: Wingless and fighting males in fig wasps and other insects. In Reproductive competition, mate choice and sexual selection in insects Edited by: Blum MS, Blum NA. New York: Academic Press; 1979:167-220.

4I. Weiblen GD: How to be a fig wasp. Annu Rev Entomol 2002, 47(I):299-330.

42. Mombaerts P: Seven-transmembrane proteins as odorant and chemosensory receptors. Science I999, 286(5440):707-7I I.

43. Hill CA, Fox AN, Pitts RJ, Kent LB, Tan PL, Chrystal MA, Cravchik A, Collins FH, Robertson HM, Zwiebel LJ: G Protein-coupled receptors in Anopheles gambiae. Science 2002, 298(559I): I76-I78.

44. Robertson HM, Warr CG, Carlson JR: Molecular evolution of the insect chemoreceptor gene superfamily in Drosophila melanogaster. Proc Natl Acad Sci USA 2003, I 00(Suppl 2): | 4537- | 4542.

45. Robertson HM, Wanner KW: The chemoreceptor superfamily in the honey bee Apis mellifera: Expansion of the odorant, but not gustatory, receptor family. Genome Res 2006, I 6( I I): I395-1403.

46. Jones WD, Nguyen TA, Kloss B, Lee KJ, Vosshall LB: Functional conservation of an insect odorant receptor gene across 250 million years of evolution. Curr Biol 2005, I 5(4):RI|9-RI2I.
47. Gao Q, Chess A: Identification of candidate Drosophila olfactory receptors from genomic DNA sequence. Genomics 1999 , 60(1):31-39.

48. Vosshall LB, Amrein H, Morozov PS, Rzhetsky A, Axel R: A spatial map of olfactory receptor expression in the Drosophila antenna. Cell I999, 96(5):725-736

49. Clyne PJ, Warr CG, Freeman MR, Lessing D, Kim J, Carlson JR: A novel family of divergent seven-transmembrane proteins: Candidate odorant receptors in Drosophila. Neuron 1999, 22(2):327-338.

50. Pitts RJ, Fox AN, Zwiebel LJ: A highly conserved candidate chemoreceptor expressed in both olfactory and gustatory tissues in the malaria vector Anopheles gambiae. Proc Natl Acad Sci USA 2004, I 0 I ( I 4):5058-5063.

5I. Krieger J, Raming K, Dewer YM, Bette S, Conzelmann S, Breer H: A divergent gene family encoding candidate olfactory receptors of the moth Heliothis virescens. Eur I Neurosci 2002, I 6(4):619-628.

52. Krieger J, Klink O, Mohl C, Raming K, Breer H: A candidate olfactory receptor subtype highly conserved across different insect orders. J Comp Physiol A Neuroethol Sens Neural Behav Physiol 2003, I 89(7):519-526

53. Melo ACA, Rutzler M, Pitts RJ, Zwiebel LJ: Identification of a chemosensory receptor from the yellow fever mosquito, Aedes aegypti, that is highly conserved and expressed in olfactory and gustatory organs. Chem Senses 2004, 29(5):403-4I0.

54. Xia $Y, Z$ wiebel LJ: Identification and characterization of an odorant receptor from the West Nile virus mosquito, Culex quinquefasciatus. Insect Biochem Molec 2006, 36(3): I69-I76.

55. Larsson MC, Domingos Al, Jones WD, Chiappe ME, Amrein H, Vosshall LB: Or83b encodes a broadly expressed odorant receptor essential for Drosophila olfaction. Neuron 2004, 43(5):703-7|4.

56. Benton R, Sachse S, Michnick SW, Vosshall LB: Atypical membrane topology and heteromeric function of Drosophila odorant receptors in vivo. Plos Biol 2006, 4(2):e20.

57. Neuhaus EM, Gisselmann G, Zhang W, Dooley R, Stortkuhl K, Hatt $\mathrm{H}$ : Odorant receptor heterodimerization in the olfactory system of Drosophila melanogaster. Nat Neurosci 2005, 8(I):I5-I7.

58. Fox AN, Pitts RJ, Robertson HM, Carlson JR, Zwiebel LJ: Candidate odorant receptors from the malaria vector mosquito Anopheles gambiae and evidence of down-regulation in response to blood feeding. Proc Natl Acad Sci USA 200I, 98(25): | 4693- | 4697.

59. Krieger J, Grosse-Wilde E, Gohl T, Dewer YME, Raming K, Breer H: Genes encoding candidate pheromone receptors in a moth (Heliothis virescens). Proc Natl Acad Sci USA 2004, I 0 I (32): I I 845-I I 850.

60. Sakurai $T$, Nakagawa T, Mitsuno $H$, Mori $H$, Endo $Y$, Tanoue $S$, Yasukochi $Y$, Touhara $K$, Nishioka T: Identification and functional characterization of a sex pheromone receptor in the silkmoth Bombyx mori. Proc Natl Acad Sci USA 2004 I0I(47): I 6653-I6658.

6I. Dekker T, Ibba I, Siju KP, Stensmyr MC, Hansson BS: Olfactory shifts parallel superspecialism for toxic fruit in Drosophila melanogaster sibling, D. sechellia. Curr Biol 2006, I 6(I): I0I-I09.

62. McBride CS: Rapid evolution of smell and taste receptor genes during host specialization in Drosophila sechellia. Proc Natl Acad Sci USA 2007, I 04( I 2):4996-5001.

63. Wistrand M, Kall L, Sonnhammer ELL: A general model of G protein-coupled receptor sequences and its application to detect remote homologs. Protein Sci 2006, I 5(3):509-52I.

64. Swofford D: PAUP*: Phylogenetic Analysis Using Parsimony (*and Other Methods), Version 4.0bl0. Sunderland: Sinauer Associates; 2002.

65. Yang Z: PAML 4: Phylogenetic analysis by maximum likelihood. Mol Biol Evol 2007, 24(8): |586-159|.

66. Yang Z: Likelihood ratio tests for detecting positive selection and application to primate lysozyme evolution. Mol Biol Evol 1998, I 5(5):568-573.

67. Yang Z: Inference of selection from multiple species alignments. Curr Opin Genet Dev 2002, I 2(6):688-694.

68. Nei M, Gojobori T: Simple methods for estimating the numbers of synonymous and nonsynonymous nucleotide substitutions. Mol Biol Evol I986, 3(5):4I8-426. 
69. Ohta T: Synonymous and nonsynonymous substitutions in mammalian genes and the nearly neutral theory. J Mol Evol 1995, 40(I):56-63.

70. Tajima F: Simple methods for testing the molecular evolutionary clock hypothesis. Genetics 1993, I35(2):599-607.

7I. Sharp PM, Li WH: On the rate of DNA sequence evolution in Drosophila. J Mol Evol I989, 28(5):398-402.

72. Sharp $\mathrm{PM}$, $\mathrm{Li} \mathrm{WH}$ : The rate of synonymous substitution in enterobacterial genes is inversely related to codon usage bias. Mol Biol Evol 1987, 4(3):222-230.

73. Kimura M: The Neutral Theory of Molecular Evolution. Cambridge: Cambridge University Press; 1983.

74. Tajima F: Statistical method for testing the neutral mutation hypothesis by DNA polymorphism. Genetics 1989 I 23(3):585-595.

75. Fu YX, Li WH: Statistical tests of neutrality of mutations. Genetics 1993, I33(3):693-709.

76. Braverman JM, Hudson RR, Kaplan NL, Langley CH, Stephan W: The hitchhiking effect on the site frequency spectrum of DNA polymorphisms. Genetics 1995, I40(2):783-796.

77. Ferguson SSG: Evolving concepts in $\mathbf{g}$ protein-coupled receptor endocytosis: The role in receptor desensitization and signaling. Pharmacol Rev 200I, 53(I): I-24

78. Ohguro H, Rudnicka-Nawrot M, Zhao X, Taylor JA, Walsh KA, Palczewski K: Structural and enzymatic aspects of rhodopsin phosphorylation. J Biol Chem 1996, 27 I(9):52 I5-5224.

79. Chao TH, Ember JA, Wang M, Bayon Y, Hugli TE, Ye RD: Role of the second extracellular loop of human $\mathrm{C} 3 \mathrm{a}$ receptor in agonist binding and receptor function. I Biol Chem 1999 274(14):972|-9728.

80. Capendeguy O, Chodanowski P, Michielin O, Horisberger JD: Access of extracellular cations to their binding sites in $\mathrm{Na}$, $\mathrm{K}$ ATPase: Role of the second extracellular loop of the \{alpha\} subunit. I Gen Physiol 2006, I 27(3):34|-352.

8I. Dunipace L, Meister S, McNealy C, Amrein H: Spatially restricted expression of candidate taste receptors in the Drosophila gustatory system. Curr Biol 200 I, I I ( I I):822-835

82. Scott K, Brady R, Cravchik A, Morozov P, Rzhetsky A, Zuker C, Axel $\mathrm{R}$ : A chemosensory gene family encoding candidate gustatory and olfactory receptors in Drosophila. Cell 200I, I04(5):66 I-673

83. Taylor BJ: Sexually dimorphic neurons of the terminalia of Drosophila melanogaster: II. Sex-specific axonal arborizations in the central nervous system. J Neurogenet 1989, 5(3): |93-2। 3

84. Kwon HW, Lu T, Rutzler M, Zwiebel LJ: Olfactory responses in a gustatory organ of the malaria vector mosquito Anopheles gambiae. Proc Natl Acad Sci USA 2006, I 03(36): | 3526- | 353 |

85. Cook JM, Compton SG, Herre EA, West SA: Alternative mating tactics and extreme male dimorphism in fig wasps. Proc Roy Soc B-Biol Sci 1997, 264(1382):747-754.

86. Zammit J, Schwarz MP: Intersexual sibling interactions and male benevolence in a fig wasp. Anim Behav 2000, 60(5):695-70I.

87. Greeff JM, van Noort S, Rasplus JY, Kjellberg F: Dispersal and fighting in male pollinating fig wasps. Comptes Rendus Biologies 2003 326(I): $121-130$

88. Gould SJ, Vrba ES: Exaptation; A missing term in the science of form. Paleobiology 1982, 8(I):4-I5

89. Suzuki Y, Gojobori T: A method for detecting positive selection at single amino acid sites. Mol Biol Evol 1999, I 6(10): I3 I5-1328.

90. Sun H, Merugu S, Gu X, Kang YY, Dickinson DP, Callaerts P, Li W-H: Identification of essential amino acid changes in paired domain evolution using a novel combination of evolutionary analysis and in vitro and in vivo studies. Mol Biol Evol 2002 I 9(9): |490-I500.

91. Czerny T, Busslinger M: DNA-binding and transactivation properties of Pax-6: three amino acids in the paired domain are responsible for the different sequence recognition of Pax-6 and BSAP (Pax-5). Mol Cell Biol I995, I 5(5):2858-287I.

92. Jun S, Desplan C: Cooperative interactions between paired domain and homeodomain. Development 1996, I 22(9):2639-2650.

93. Hughes AL, Ota T, Nei M: Positive Darwinian selection promotes charge profile diversity in the antigen-binding cleft of class I major-histocompatibility-complex molecules. Mol Biol Evol 1990, 7(6):515-524.
94. Sha WC, Nelson CA, Newberry RD, Pullen JK, Pease LR, Russell JH, Loh DY: Positive selection of transgenic receptor-bearing thymocytes by $\mathrm{Kb}$ antigen is altered by $\mathrm{Kb}$ mutations that involve peptide binding. Proc Natl Acad Sci USA 1990, 87(16):6186-6190

95. Bouček Z: Australian Chalcidoidea (Hymenoptera): A Biosystematic Revision of Genera and Fourteen Families, with a Reclassification of Species (Fig wasp section). Wallingford: $\mathrm{CAB}$, International; 1988

96. Bouček Z: The genera of chalcidoid wasps from Ficus fruit in the New World. J Nat Hist 1993, 27(I): I73-217.

97. West SA, Herre EA, Windsor DM, Green PRS: The ecology and evolution of the New World non-pollinating fig wasp communities. J Biogeogr 1996, 23(4):447-458.

98. Rasplus JY, Kerdelhue C, Le Clainche I, Mondor G: Molecular phylogeny of fig wasps: Agaonidae are not monophyletic. $C R$ Acad Sci Serie III Sci Vie 1998, 32 I (6):5 I 7-526.

99. Ohta $\mathrm{T}$ : The nearly neutral theory of molecular evolution. Annu Rev Ecol S 1992, 23(I):263-286.

100. Akashi $\mathrm{H}$ : Inferring weak selection from patterns of polymorphism and divergence at "silent" sites in Drosophila DNA. Genetics 1995, I39(2): 1067-1076.

10I. Akashi $\mathrm{H}$ : Inferring the fitness effects of DNA mutations from polymorphism and divergence data: statistical power to detect directional selection under stationarity and free recombination. Genetics 1999, I5 I(I):221-238.

102. Akashi H: Molecular evolution between Drosophila melanogaster and $D$. simulans: Reduced codon bias, faster rates of amino acid substitution, and larger proteins in D. melanogaster. Genetics 1996, I 44(3): I 297-I 307.

103. Kerdelhue C, Rasplus JY: Non-pollinating Afrotropical fig wasps affect the fig-pollinator mutualism in Ficus within the subgenus Sycomorus. Oikos 1996, 75(I):3-14.

104. Machado CA, Jousselin E, Kjellberg F, Compton SG, Herre EA: Phylogenetic relationships, historical biogeography and character evolution of fig-pollinating wasps. Proc Roy Soc B-Biol Sci 200I, 268(I468):685-694.

105. Rand DM, Haney RA, Fry AJ: Cytonuclear coevolution: the genomics of cooperation. Trends Ecol Evol 2004, I 9(I 2):645-653

106. Rand DM, Fry AJ, Sheldahl L: Nuclear-mitochondrial epistasis and Drosophila aging: Introgression of Drosophila simulans mtDNA modifies longevity in $D$. melanogaster nuclear backgrounds. Genetics 2006, I72(I):329-34I.

107. Zeviani M, Spinazzola A, Carelli V: Nuclear genes in mitochondrial disorders. Curr Opin Genet Dev 2003, I3(3):262-270.

108. Roubertoux PL, Sluyter F, Carlier M, Marcet B, Maarouf-Veray F, Cherif C, Marican C, Arrechi P, Godin F, Jamon M, et al.: Mitochondrial DNA modifies cognition in interaction with the nuclear genome and age in mice. Nat Genet 2003, 35(I):65-69.

109. Mishmar D, Ruiz-Pesini E, Mondragon-Palomino M, Procaccio V, Gaut $B$, Wallace DC: Adaptive selection of mitochondrial complex I subunits during primate radiation. Gene 2006, 378: I I-I8.

I10. Akashi H: Synonymous codon usage in Drosophila melanogaster: Natural selection and translational accuracy. Genetics 1994, I36(3):927-935

III. Grosjean H, Fiers W: Preferential codon usage in prokaryotic genes: the optimal codon-anticodon interaction energy and the selective codon usage in efficiently expressed genes. Gene 1982, I 8(3): 199-209.

I 12. Sharp PM, Tuohy TMF, Mosurski KR: Codon usage in yeast: cluster analysis clearly differentiates highly and lowly expressed genes. Nucleic Acids Res 1986, I 4( I3):5|25-5|43.

I 13. Shields DC, Sharp PM, Higgins DG, Wright F: "Silent" sites in Drosophila genes are not neutral: evidence of selection among synonymous codons. Mol Biol Evol 1988, 5(6):704-7l6.

I14. White BN, Tener GM, Holden J, Suzuki DT: Analysis of tRNAs during the development of Drosophila. Dev Biol 1973, 33(I): 185-195.

II5. Moriyama EN, Powell JR: Codon usage bias and tRNA abundance in Drosophila. I Mol Evol 1997, 45(5):5 |4-523.

I16. Andersson SG, Kurland CG: Codon preferences in free-living microorganisms. Microbiol Rev 1990, 54(2): 198-210.

II7. Bulmer M: The selection-mutation-drift theory of synonymous codon usage. Genetics 1991, I29(3):897-907

I 18. Gonzalez F, Romani S, Cubas P, Modolell ], Campuzano S: Molecular analysis of the asense gene, a member of the achaete-scute 
complex of Drosophila melanogaster, and its novel role in optic lobe development. EMBO J 1989, 8(I 2):3553-3562.

1 19. Fitch DH, Strausbaugh LD: Low codon bias and high rates of synonymous substitution in Drosophila hydei and D. melanogaster histone genes. Mol Biol Evol 1993, I0(2):397-4I3.

120. Nozawa M, Nei M: Evolutionary dynamics of olfactory receptor genes in Drosophila species. Proc Natl Acad Sci USA 2007, 104(I7):7|22-7|27.

121. Guo S, Kim J: Molecular evolution of Drosophila odorant receptor genes. Mol Biol Evol 2007, 24(5): I | 98- 1207.

122. Stensmyr MC, Dekker T, Hansson BS: Evolution of the olfactory code in the Drosophila melanogaster subgroup. Proc Roy Soc BBiol Sci 2003, 270(I53I):2333-2340.

123. McDonald JH, Kreitman M: Adaptive protein evolution at the Adh locus in Drosophila. Nature 1991, 35 I(6328):652-654

124. Simonsen KL, Churchill GA, Aquadro CF: Properties of statistical tests of neutrality for DNA polymorphism data. Genetics 1995, I 4 I(I):413-429.

125. Krogh A, Larsson B, von Heijne G, Sonnhammer EL: Predicting transmembrane protein topology with a hidden Markov model: application to complete genomes. J Mol Biol 200I, 305(3):567-580.

126. Sonnhammer EL, von Heijne G, Krogh A: A hidden Markov model for predicting transmembrane helices in protein sequences. Proc Int Conf Intell Syst Mol Biol 1998, 6: I75-182.

127. Thompson JD, Higgins DG, Gibson TJ: CLUSTAL W: improving the sensitivity of progressive multiple sequence alignment through sequence weighting, position-specific gap penalties and weight matrix choice. Nucleic Acids Res 1994, 22(22):4673-4680.

128. Crooks GE, Hon G, Chandonia JM, Brenner SE: WebLogo: A sequence logo generator. Genome Res 2004, I 4(6): I | 88- I I 90.

129. Schneider TD, Stephens RM: Sequence logos: a new way to display consensus sequences. Nucleic Acids Res 1990, 18(20):6097-6100.

130. Naylor GJP, Brown WM: Amphioxus mitochondrial DNA, chordate phylogeny, and the limits of inference based on comparisons of sequences. Systematic Biol 1998, 47:6I-76.

131. Kumar S, Gadagkar SR: Disparity index: A simple statistic to measure and test the homogeneity of substitution patterns between molecular sequences. Genetics 200I, | 58(3): | $32|-| 327$.

132. Tamura K, Dudley J, Nei M, Kumar S: MEGA4: Molecular evolutionary genetics analysis (MEGA) software version 4.0. Mol Biol Evol 2007, 24(8): 1596-1599.

133. Nene V, Wortman JR, Lawson D, Haas B, Kodira C, Tu Z, Loftus B, $X_{i} Z$, Megy K, Grabherr M, et al.: Genome sequence of Aedes aegypti, a major arbovirus vector. Science 2007, 316(5832): $1718-1723$.

134. Zhang J, Rosenberg HF, Nei M: Positive Darwinian selection after gene duplication in primate ribonuclease genes. Proc Natl Acad Sci USA 1998, 95(7):3708-3713.

135. Jukes TH, Cantor CR: Evolution of protein molecules. New York: Academic Press; 1969.

136. Wright $F$ : The 'effective number of codons' used in a gene. Gene 1990, 87(I):23-29

137. Morton BR: Chloroplast DNA codon use: evidence for selection at the Psb A locus based on tRNA availability. J Mol Evol 1993, 37(3):273-280.

138. Rozas J, Sanchez-DelBarrio JC, Messeguer X, Rozas R: DnaSP, DNA polymorphism analyses by the coalescent and other methods. Bioinformatics 2003, I9( I8):2496-2497.

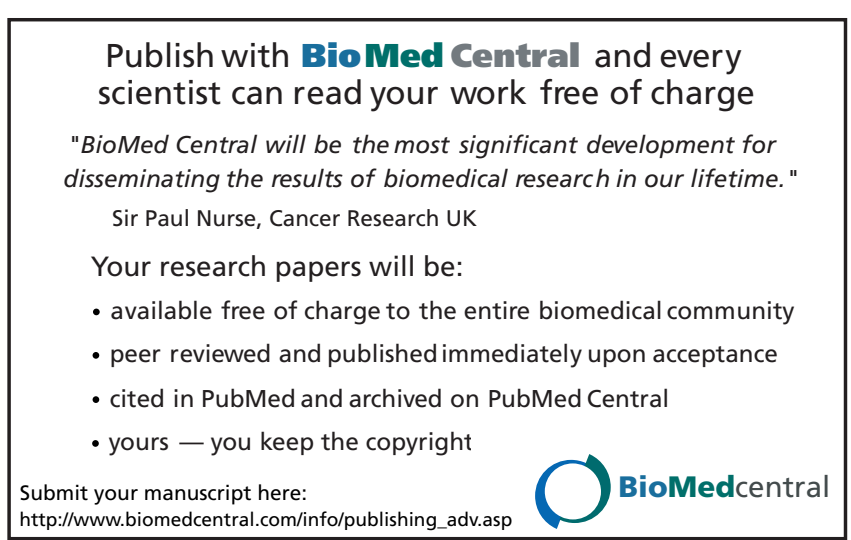

